\title{
Changes in kinesiostabilogram parameters and movement speed of stroke patients while increasing their physical activity due to the use of biofeedback method
}

\author{
Victoria Zaborova (1,2), Anatoly Fesyun (3), Konstantin Gurevich (3,4,5), Alevtina \\ Oranskaya (4), Alexey Rylsky (6), Kira Kryuchkova (1), Vladimir Malakhovskiy (1), \\ Dmitry Shestakov (7)
}

(1) Department of Sports Medicine and Medical Rehabilitation, Sechenov First Moscow State Medical University (Sechenov University), Moscow, Russia; (2) Sports Adaptology Laboratory, Moscow Institute of Physics and Technology (National Research University), Moscow Region, Dolgoprudniy, Russia: (3) FSBI "National Medical Research Center for Rehabilitation and Resortology" Ministry of Public Health of Russia, Moscow, Russia; (4) UNESCO chair "Healthy life style for sustainable development" "Moscow State University of Medicine and Dentistry. A.I. Evdokimov", Ministry of Health of the Russian Federation, Moscow, Russia; (5) Research Institute of Healthcare Organization and Medical Management of the Moscow Department of Healthcare, Moscow, Russia; (6) Moscow scientific and practical center for medical rehabilitation, rehabilitation and sports medicine, Department of Health of Moscow, Moscow, Russia; (7) Department of Orthopedics and Complex Trauma of the Moscow Clinical Research Center A.S. Loginov, Moscow, Russia.

This article is distributed under the terms of the Creative Commons Attribution Noncommercial License (CC BY-NC 4.0) which permits any noncommercial use, distribution, and reproduction in any medium, provided the original author(s) and source are credited.

\begin{abstract}
Balance disorders are complications of stroke survivors. Aim of this study was the establish effectiveness of the biofeedback approach. In this intervention study 245 patients with early diagnosis of acute disturbance of cerebral circulation (ADCC) were examined. Patients able to move independently were treated by standard conservative ADCC therapy on an outpatient approach, but they continued to have problems with coordination of movement in upright position. Then they were submitted to an increasing physical activity based on five sessions of biofeedback, i.e., a complex rehabilitation of patients with motor pathology "Trust-M" according to TU 9442-001-63704475-2010. Mobility rates were assessed using a web camera. Patients' quality of life was evaluated by SF-36 questionnaire and the Hospital Anxiety and Depression Scale (HADS). All parameters were recorded before and after 5 sessions of biofeedback. After treatment, the stability indicators improved and all patients showed a significant increase in motion rate and quality of life. At the same time, the severity of pain and of depression and anxiety decreased. Negative correlations of average strength between the quadrant and patient HADS scaling rates were obtained. In conclusion, our work shows effectiveness of the biofeedback technique for correcting coordination in stroke survivors.
\end{abstract}

Key Words: Statokinesiogram; biofeedback; stroke; quality of life; stability; balance; fall.

Approximately every sixth elderly inhabitant of the Earth has at least once suffered a stroke or an acute disturbance of cerebral circulation. Along with coronary heart disease, stroke is the main cause of potentially lost years of life and physical health., ${ }^{1,2}$ Approximately $90 \%$ of patients after a stroke have problems of maintaining equilibrium. ${ }^{3-5}$ In addition to injuries, those who fall have limited energy, increased vulnerability and fear of falling. ${ }^{6,7}$ They form barriers to social and public activity and adversely affect the quality of life. ${ }^{8-10}$ It is difficult to overcome them, as patients require significant cognitive and emotional adaptation to successfully adopt survival strategies. ${ }^{11-13}$

The problem of maintaining equilibrium in movement and/or static vertical position is relevant for people who have suffered a stroke or an acute disturbance of cerebral circulation. Annually, more and more people need rehabilitation procedures after a stroke, including those 
due to balance disorders, and the cost of supervising stroke patients who need constant care is high and will be presumably growing in future. ${ }^{1,14}$ To reduce the cost and increase the effectiveness of rehabilitation after a stroke, new methods of rehabilitation are being developed. Seven major risk factors for falling among stroke survivors have been identified in the community, i.e. impaired mobility, decreased balance, use of psychotropic drugs, self-care disability, depression, cognitive impairment, and history of falls. ${ }^{15,16}$

Since locomotion is the result of complex dynamic interactions between the feedback mechanisms and the brain central controller, the best rehabilitation methods require a fundamental understanding of these features of the human gait coordination. ${ }^{17-19}$ Therefore, methods using the principle of biological feedback (BFB) are increasingly being used for the rehabilitation of stroke patients. This effect allows to include various sensory data, personal experience, training, particularly motor training, and show that there is a connection between biofeedback and the effectiveness of stroke patients' rehabilitation. ${ }^{20-22}$ The purpose of this work was to study the effectiveness of biofeedback in stroke patients' rehabilitation to increase their stability in an upright position.

\section{Materials and Methods}

The study was approved by the clinical research ethics committee and was conducted in accordance with the Declaration of Helsinki. All the patients participating in the study gave an informed voluntary written consent. The study was conducted within the period of 2018-2019, in the laboratory of biological feedback (BFB) of Moscow Scientific and Practical Center for Medical Rehabilitation, Restorative and Sports Medicine, Moscow Department of Health (office No. 7). 245 patients with early diagnosed acute disturbance of cerebral circulation (ADCC), or stroke, were examined. Patients were able to move independently, were treated on an outpatient basis; however, all of them had continuous motion coordination problems in an upright position. Patients received standard conservative treatment according to the standard protocol of the Russian Federation. In addition to it, the method of increasing physical activity was used, based on biofeedback - a complex for diagnosing, treatment and rehabilitation of patients with motor pathology "TrustM" according to TU 9442-001-63704475-2010 (registration certificate for a medical device dated December 16, 2016 Fed No. 2010/08881). In total, 5 sessions of biofeedback were conducted. The study included only those patients who attended all the sessions. The biofeedback sessions were conducted as follows: Patients were in the booth in front of a monitor that shows the booth (top view), the position of the patient and the task (the point where the patient is to move). Accordingly, all the tasks were located at different angles to face the patient, and, performing them,

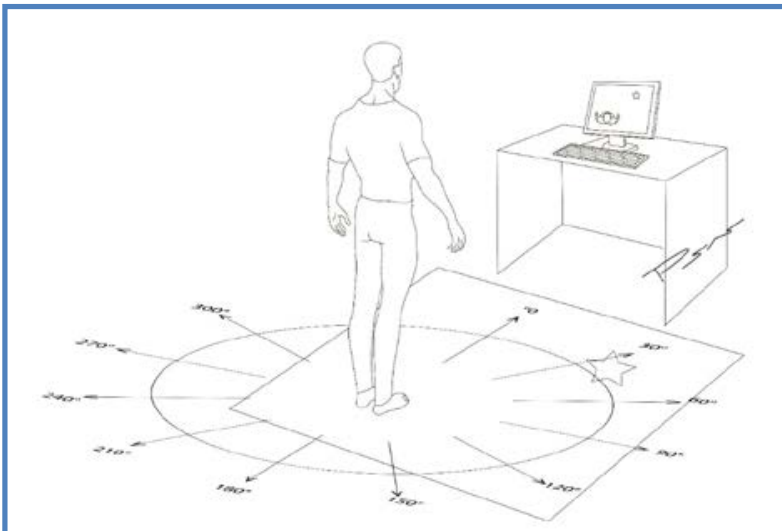

Fig 1. An example of the directional pattern (side view).

he was forced to move in different directions. In total, the session lasted 720 seconds, during the session the patient receiving 36 tasks. The directional pattern was obtained by smoothing the obtained values. When interpreted: "zero" was the reference point "in the face of the patient", the direction was clockwise. An example of the directional pattern is presented in Figure. 1.

Stabilometric examination was carried out on the TrustM equipment according to TU 9442-001-63704475-2010 (registration certificate for a medical device dated December 16, 2016 No. FRS 2010/08881). US research protocol was used, recording time 60 seconds. ${ }^{23-24}$ The person assumed a natural standing position with his upper limbs hanging down along the body. The angle of support was natural, the patient's feet parallel. The patient was standing with his eyes open. The subject stopped trying to maintain visual focus at the starting point in front of him, at a distance of 1 meter, at an eye level. The correct measurement was preceded by a 30-second "training" period to stabilize balance, and then the test readings were recorded. During the experiment the researcher was always behind the patient. The patient's movement rates during the biofeedback session were evaluated along 4 quadrants - I $\left(0^{\circ}-89^{\circ}\right)$, II $\left(90^{\circ}-179^{\circ}\right)$, III $\left(180^{\circ}-269\right.$ $\left.{ }^{\circ}\right)$, IV $\left(270^{\circ}-359^{\circ}\right)$ using a webcam. The patient's quality of life was assessed by means of SF-36 questionnaire. $^{25}$ The Hospital Anxiety and Depression Scale (HADS) was also used in this work. ${ }^{26}$ All were recorded twice: before treatment and after 5 sessions of biofeedback. Statistical processing of the research results was carried out in Excel 2007 and Statistica 13. The laws of parameter distribution were established on the basis of the Kolmogorov-Smirnov criterion. Statokinetic parameters did not contradict the hypothesis of a normal distribution. Dispersions were compared with Fisher Ftest. For equality of variances, Student's t-test was used, with inequality, Welch's T-test was used. The parameters of quality of life and the hospital scale of anxiety and depression were compared on the of the Kraxler-Wallis test. The Spearman correlation coefficient was 
Table 1. Characterization of patients included in the study

\begin{tabular}{llllll}
\hline Age & Men & & Women & Total \\
\hline & $\begin{array}{l}\text { Absolute } \\
\text { number }\end{array}$ & Relative number & $\begin{array}{l}\text { Absolute } \\
\text { number }\end{array}$ & Relative number & \\
\hline$\leq 50$ & 15 & $6.1 \%$ & 17 & $6.9 \%$ & $13.1 \%$ \\
$51-60$ & 28 & $11.4 \%$ & 31 & $12.7 \%$ & $24.1 \%$ \\
$61-70$ & 34 & $13.9 \%$ & 65 & $26.5 \%$ & $40.4 \%$ \\
$\geq 71$ & 24 & $9.8 \%$ & 31 & $12.7 \%$ & $22.4 \%$ \\
Total & 97 & $41.2 \%$ & 148 & $58.8 \%$ & $100.0 \%$ \\
\hline
\end{tabular}

calculated. The differences with $\mathrm{p}<0.05$ were considered significant.

\section{Results}

The duration of stroke was $230 \pm 42.1$ days. The average age of the patients was $60.7 \pm 11.6$ years. There were 97 men, 148 women (Table 1). Ischemic stroke - 72.1\%; hemorrhagic 27.9\%. All the patients have showed hemispheric nidus localization: the right hemisphere 44.9\%; the left one - $55.1 \%$. After treatment, according to the results of stabilokinesiogram, there was a significant increase in the common center of pressure (CCP) and acceleration of the common center of pressure (ACCP) in the frontal and sagittal planes (Table 2). These changes are combined with the observed significant increase in the width and length of the ellipse. At the same time, the length of the stabilokinesiogram increases. However, this reduces the ratio of the length of the statokinesiogram to its area. The analysis of frequency characteristics of the stabilokinesiogram (Table 3) indicates a significant decrease in the proportion of high-frequency (non-directional) oscillations after. The increase in the patient's movement range described in Table 4 correlates with an increase in the extent of low-frequency oscillations $(r=0.89$, $p$ $<0.001)$ and a decrease in the extent of high-frequency oscillations $(r=-0.75, p<0.001)$. As per data shown in table 3, all the patients has shown a significant increase in speed. According to the Kraskler-Wallis criterion, after treatment, the quality of life of patients on the SF36 scale improved (Table 5). As a result of treatment, such indicators of life quality as physical functioning, role-based functioning, general health, and vitality increased. At the same time, the severity of pain decreased. The severity of depression and anxiety on the HADS scale also decreased. Negative correlations of the average strength between the speed of movement of patients in quadrants and the HADS scale were obtained (Table 6). Both before and after the treatment, patients with a higher score for depression or anxiety are characterized by a decrease in the speed of movement.

Table 2. Change in the Linear Parameters of Stabilogram Before and After Sessions

\begin{tabular}{|c|c|c|c|c|c|}
\hline \multirow[t]{2}{*}{ Parameter } & \multicolumn{2}{|c|}{ before } & \multicolumn{2}{|c|}{ after } & \multirow[t]{2}{*}{$\mathrm{p}$} \\
\hline & Average & $\begin{array}{c}\text { Error } \\
\text { average }\end{array}$ & Average & $\begin{array}{c}\text { Error } \\
\text { average }\end{array}$ & \\
\hline $\begin{array}{l}\text { Maximum amplitude of oscillations of the } \\
\text { common center of pressure in frontal plane, } \\
\mathrm{mm}\end{array}$ & 17.3 & 1.0 & 23.4 & 1.3 & 0.000 \\
\hline $\begin{array}{l}\text { Maximum amplitude of oscillations of the } \\
\text { common sagittal pressure center in plane, mm }\end{array}$ & 25.4 & 1.2 & 30.2 & 1.1 & 0.004 \\
\hline $\begin{array}{l}\text { Maximum amplitude of acceleration } \\
\text { oscillations of the common center of pressure } \\
\text { in frontal plane, } \mathrm{mm}\end{array}$ & 0,584 & 0,034 & 0,795 & 0,043 & 0,000 \\
\hline $\begin{array}{l}\text { Maximum amplitude of acceleration } \\
\text { oscillations of the common center of pressure } \\
\text { in sagittal plane, mm }\end{array}$ & 0.862 & 0.041 & 1.029 & 0.041 & 0.005 \\
\hline Length of statokinesiogram, & 646.6 & 21.8 & 971.6 & 48.5 & 0.000 \\
\hline Ellipse length, mm & 17.80 & 0.94 & 21.61 & 0.96 & 0.006 \\
\hline Ellipse width, mm & 10.32 & 0.57 & 12.95 & 0.61 & 0.002 \\
\hline Ratio of length of statokinesiogram to its area & 7.35 & 0.40 & 6.07 & 0.34 & 0.022 \\
\hline $\begin{array}{l}\text { The ratio of the length of the statokinesiogram } \\
\text { to its area }\end{array}$ & 7.351 & 0.405 & 6.073 & 0.343 & 0.022 \\
\hline
\end{tabular}


Table 3. Change of Stabilogram Frequency Parameters Before and After Sessions

\begin{tabular}{lcccccr|}
\hline \multicolumn{1}{c}{ Parameter } & \multicolumn{3}{c}{ before } & \multicolumn{3}{c}{ after } \\
\hline & Average & $\begin{array}{c}\text { Error } \\
\text { average }\end{array}$ & Average & $\begin{array}{c}\text { Error } \\
\text { average }\end{array}$ \\
\hline $\begin{array}{l}\text { Amplitude of the 1st maximum of the spectrum along } \\
\text { the frontal component, mm }\end{array}$ & 0.831 & 0.075 & 1.196 & 0.090 & 0.002 \\
$\begin{array}{l}\text { Frequency of the 2nd maximum of the spectrum by } \\
\text { the frontal component, hertz }\end{array}$ & 0.284 & 0.017 & 0.218 & 0.016 & 0.007 \\
$\begin{array}{l}\text { Amplitude of the 2nd maximum of the spectrum along } \\
\text { the frontal component, mm }\end{array}$ & 0.611 & 0.040 & 0.838 & 0.056 & 0.001 \\
$\begin{array}{l}\text { Amplitude of the 3d maximum of the spectrum along } \\
\text { the frontal component, mm }\end{array}$ & 0.457 & 0.024 & 0.657 & 0.047 & 0.000 \\
$\begin{array}{l}\text { Frequency of the 3rd maximum of the spectrum for } \\
\text { the sagittal component, hertz }\end{array}$ & 0.339 & 0.017 & 0.426 & 0.021 & 0.001 \\
$\begin{array}{l}\text { Frequency of the 1st spectrum maximum along the } \\
\text { vertical component, hertz }\end{array}$ & 4.486 & 0.198 & 3.623 & 0.228 & 0.005 \\
$\begin{array}{l}\text { Amplitude of the 1st maximum of the spectrum along } \\
\text { the vertical component, mm }\end{array}$ & 0.022 & 0.001 & 0.030 & 0.005 & 0.048 \\
$\begin{array}{l}\text { Frequency of the 2nd spectrum maximum along the } \\
\text { vertical component, hertz }\end{array}$ & 4.626 & 0.198 & 3.574 & 0.222 & 0.001 \\
$\begin{array}{l}\text { Frequency of the 3d spectrum maximum along the } \\
\text { vertical component, hertz }\end{array}$ & 4.772 & 0.181 & 3.989 & 0.209 & 0.005 \\
$\begin{array}{l}\text { The level of 60\% of the spectrum power by the } \\
\text { vertical component, watts }\end{array}$ & 5.88 & 0.09 & 5.32 & 0.12 & 0.000 \\
\hline
\end{tabular}

\section{Discussion}

The main problem in the rehabilitation of stroke patients is the assessment of likelihood of their fall. Currently, there is no single test or methodological approach that would show the likelihood of falls after ADCC. The Berg Balance Scale is the commonly used clinical assessment to determine the risk of falls after a stroke. ${ }^{27,28}$ There are works dedicated to studies of relationship between patient's movement speed and likelihood of falling. It has been shown that even if patients move at a convenient pace, this does not reduce the risk of falling. However, patients who move faster after a stroke have a lower risk of falling than those who move slowly. ${ }^{29}$ Wearing comfortable shoes does not significantly affect the risk of falling. ${ }^{30}$ Gait speed (for example, in a 10 -meter walk test) is a common instrumental assessment to determine the risk of falls after stroke. ${ }^{31}$ Measures of step variability and "smoothness" during gait were more informative in determining the likelihood of falls after a stroke than other clinical measurements. ${ }^{32}$ However, a number of researchers believe that to assess the risk of falls it is necessary to simultaneously use both clinical scales and methods of balance assessment. ${ }^{33}$ A number of works show the relationship between the equilibrium function and the fall after a stroke. ${ }^{34-36}$ Also important is the change in position of the body balance in space. Thus, people who had a stroke showed a greater displacement of the pelvis in walking compared with healthy ones. ${ }^{37}$ Based on the available publications, in a systematic review it is proposed to use the ratio of mobility and balance variables. ${ }^{15}$ That is why in the course of our research we have studied both the indicators of stabilometry and the speed of patients' movement. We have found a decrease in the ratio of the length of statokinesiogram to its area, which can be regarded as a positive clinical factor. ${ }^{38}$ As a result of rehabilitation, we have observed a decrease in the proportion of high-

Table 4. Changing in parameters of the patient's movement speed before and after exercise.

\begin{tabular}{|llllll|}
\hline Parameter & before & & after & P \\
\hline & Average & Error average & Average & $\begin{array}{l}\text { Error } \\
\text { average }\end{array}$ \\
\hline Average speed quadrant I, mm / s & 19.54 & 0.73 & 22.05 & 0.62 & 0.013 \\
Average speed quadrant II, mm/ s & 20.71 & 0.72 & 23.90 & 0.64 & 0.023 \\
Average speed quadrant III, mm/s & 21.86 & 1.60 & 51.89 & 0.64 & 0.000 \\
Average speed quadrant IV, mm/ s & 18.91 & 0.68 & 21.65 & 0.68 & 0.006 \\
\hline & & & & & \\
\hline
\end{tabular}


Table 5. Changing in parameters of the patient's movement speed before and after exercise.

\begin{tabular}{lccccc}
\hline \multicolumn{1}{c}{ Parameter } & \multicolumn{2}{c}{ before } & \multicolumn{2}{c}{ after } \\
\cline { 2 - 5 } & Average & $\begin{array}{c}\text { Error } \\
\text { average }\end{array}$ & Average & $\begin{array}{c}\text { Error } \\
\text { average }\end{array}$ \\
\hline Physical functioning, points & Scale SF-36 & & & \\
Role functioning, points & 58.58 & 2.19 & 68.24 & 2.01 & 0.016 \\
Role functioning, points & 27.54 & 3.66 & 47.29 & 3.98 & 0.004 \\
Pain, points & 44.52 & 1.99 & 31.62 & 2.42 & 0.001 \\
General health, points & 46.52 & 9.63 & 48.64 & 10.45 & 0.238 \\
Vitality, points & 49.25 & 1.76 & 58.24 & 2.12 & 0.008 \\
Social functioning, points & 56.33 & 10.54 & 52.86 & 7.94 & 0.063 \\
Emotional functioning, points & 41.64 & 9.84 & 55.81 & 4.01 & 0.054 \\
Psychological health, points & 57.97 & 6.66 & 63.45 & 2.06 & 0.090 \\
\hline & Scale HADS & & & & \\
\hline Anxiety, points & 9,189 & 0,374 & 7,324 & 0,376 & 0,007 \\
Depression, points & 7,108 & 0,322 & 5,648 & 0,325 & 0,015 \\
\hline
\end{tabular}

frequency movements against the background of an increase in speed of movement due to low-frequency movements to maintain the patient's static posture. In addition, we have ascertained an improvement in the patients' quality of life. This allowed us to make a preliminary conclusion about positive influence of the effected intervention on patients' condition. It should be noted that, according to several authors, dynamic balance estimates were better predictors of falls than static ones. ${ }^{39}$ It is believed that the dynamics of maintaining patient's equilibrium can serve as a highly informative assessment to determine the risk of falling. ${ }^{40}$ That is why, from our point of view, the most favorable predictor of positive changes in the condition of the examined patients is the positive dynamics of studied indicators. Methods of rehabilitation of stroke patients. Many methods are used to rehabilitate stroke patients. Especially relevant is the prevention of falls. According to a systematic review. ${ }^{41}$ there is currently no effective evidence that physical rehabilitation methods can reduce the risk of falling after a stroke. There are preliminary results of the effectiveness of vitamin $\mathrm{D}$, but they need a wider clinical study. Among the methods that are used for the rehabilitation of patients with ADCC, a decent place is based on the principle of biofeedback. Biofeedback (BFB) is an instrumental therapy method that allows the patient to come to understanding and controlling the reactions of his own body. ${ }^{42}$ The method of biofeedback is widely used to treat a wide variety of conditions, such as clinical pathologies, its effectiveness has been proven to affect the functional capabilities of the brain, and there is evidence of its effect on the psychophysiological characteristics of patients. ${ }^{43}$ During sessions, the patient makes various movements, and now the study of the relationship between psychology and movements is becoming increasingly relevant. There are works dedicated to the psychology of breathing, music and movement, as well as those that study smaller aspects for example, eye movements. ${ }^{44}$ Various techniques using biofeedback are widely used for the rehabilitation of patients after a stroke and ADCC. They can improve the body balance in space and reduce the number of falls. ${ }^{45}$ For example, it is proposed to use the virtual reality method, which reduces the risk of falls in stroke patients. ${ }^{46}$ Sensi-steps application is based on the principle of biofeedback, which reduces the risk of falls in stroke patients ${ }^{47} \mathrm{~A}$ similar principle underlies the telemedicine rehabilitation of patients after ADCC. ${ }^{48}$ Robotic methods and others are used. ${ }^{21,49}$ The effectiveness of a number of rehabilitation methods has been evaluated in systematic reviews..$^{50-52}$

Study limitations: The patients were monitored in a short time period. In the future, when monitoring the same cohort of patients, it is expected to evaluate the long-term

Table 6. Coefficients of correlation of indicators on the HADS scale and patient movement speeds in quadrants.

\begin{tabular}{llccrr}
\hline Parameters & & \multicolumn{2}{c}{ Quadrant travel speed } & \\
\hline Observation time & HADS scale parameters & I & II & III & IV \\
\hline \multirow{3}{*}{ Before treatment } & Anxiety & -0.74 & -0.79 & -0.73 & -0.70 \\
& Depression & -0.71 & -0.75 & -0.79 & -0.84 \\
After treatment & Anxiety & -0.83 & -0.81 & -0.88 & -0.81 \\
& Depression & -0.70 & -0.78 & -0.78 & -0.86 \\
\hline
\end{tabular}


results of the study of the effect of the biofeedback method on the stability of the posture of stroke survivors. In conclusion, the data obtained in this work tentatively show effectiveness of biofeedback method in rehabilitation of stroke patients. The technique allows to improve the equilibrium indicators and increase the speed of patients' movement.

\section{List of acronyms}

ADCC - acute disturbance of cerebral circulation HADS - hospital anxiety and depression scale CCP - common center of pressure ACCP - acceleration of the common center of pressure.

\section{Contributions of Authors}

$\mathrm{VZ}$ conception and design of the study. AO and AR acquisition, analysis and interpretation of data. KG wrote the manuscript. KK performed literature review. VM and DS article drafting and revision. AF reviewed and edited the manuscript critically, all authors approved the final version.

\section{Acknowledgments}

None.

\section{Funding}

This research did not received any specific grant from funding agencies in the public, commercial, or not-forprofit sectors.

\section{Conflict of Interest}

None

\section{Ethical Publication Statement}

We confirm that we have read the Journal's position on issues involved in ethical publication and affirm that this report is consistent with those guidelines.

\section{Corresponding Author}

Victoria Zaborova, 119991 Trubetskaya St. 8/2. Moscow, Russia.

ORCID iD: 0000-0001-5044-1152

E-mail: zaborova.va@mipt.ru

E-mails and ORCID iD of co-authors

Anatoly Fesyun: FesyunAD@nmicrk.ru

ORCID iD: 0000-0003-3097-8889

Konstantin Gurevich: kgurevich@mail.ru

ORCID iD: 0000-0002-7603-6064

Alevtina Oranskaya: anor2004@list.ru

ORCID iD: 0000-0001-7888-3745

Alexey Rylsky: 79165850111@yandex.ru

ORCID iD: 000-0002-5236-4709

Kira Kryuchkova: ira.kruchkova@mail.ru

ORCID iD: 0000-0002-1172-9695

Vladimir Malakhovskiy: tulgu@mail.ru

ORCID iD: 0000-0002-5024-5239

Dmitry Shestakov: dimitrauma@bk.ru

ORCID iD: 0000-0002-6271-3108

\section{References}

1. Benjamin EJ, Muntner P, Alonso A, Bittencourt, MS, Callaway CW, Carson AP. Heart disease and stroke statistics-2019 update: a report from the American Heart association. Circulation. 2019;e56e528.

2. Virani SS, Alonso A, Benjamin EJ, et al. Heart Disease and Stroke Statistics-2020 Update: A Report From the American Heart Association. Circulation. 2020;141(9):e139-e596. doi:10.1161/ CIR.0000000000000757.

3. Hobbs B, Artemiadis P. A review of robot-assisted lower-limb stroke therapy: unexplored paths and future directions in gait rehabilitation. Front Neurorobot. 2020;15:14-19.

4. Ataullah AHM, Naqvi IA. Cerebellar Dysfunction. In: StatPearls. Treasure Island (FL): StatPearls Publishing; September 1, 2020.

5. Levin MF. Principles of Motor Recovery After Neurological Injury Based on a Motor Control Theory. Adv Exp Med Biol. 2016;957:121-140. doi:10.1007/978-3-319-47313-0_7.

6. Schmid AA, Rittman M. Consequences of poststroke falls: activity limitation, increased dependence, and the development of fear of falling. Am J Occup Ther. 2009;63:310-6.

7. Walsh ME, Galvin R, Williams DJP, Harbison JA, Murphy S, Collins R, McCabe DJH, Crowe M, Horgan NF. The experience of recurrent fallers in the first year after stroke. Disabil Rehabil. 2019 Jan;41(2):142-149. doi: 10.1080/09638288.2017. 1381182. Epub 2017 Sep 26.

8. Batchelor FA, Mackintosh SF, Said CM, Hill KD. Falls after stroke. Int J Stroke 2012;7:482-90.

9. Price R, Choy NL. Investigating the Relationship of the Functional Gait Assessment to Spatiotemporal Parameters of Gait and Quality of Life in Individuals With Stroke. J Geriatr Phys Ther. 2019;42(4):256-264. doi:10.1519/JPT.000000000 0000173.

10. Qurat-ul-Ain, Malik AN, Amjad I. Effect of circuit gait training vs traditional gait training on mobility performance in stroke. J Pak Med Assoc. 2018;68(3):455-458.

11. Walsh M, Galvin R, Horgan NF. Fall-related experiences of stroke survivors: a metaethnography. Disabil Rehabil. 2017;39:631-40.

12. Xu T, O'Loughlin K, Clemson L, Lannin NA, Dean C, Koh G. Developing a falls prevention program for community-dwelling stroke survivors in Singapore: client and caregiver perspectives. Disabil Rehabil. 2019;41(9):1044-1054. doi:10.1080/09638288.2017.1419293.

13. Woodman P, Riazi A, Pereira C, Jones F. Social participation post stroke: a meta-ethnographic review of the experiences and views of communitydwelling stroke survivors. Disabil Rehabil. 
2014;36(24):2031-2043. doi:10.3109/09638288 . 2014.887796

14. Gardiner S, Glogowska M, Stoddart C, Pendlebury S, Lasserson D, Jackson D. Older people's experiences of falling and perceived risk of falls in the community: A narrative synthesis of qualitative research. Int J Older People Nurs. 2017;12(4):10.1111/opn.12151. doi:10.1111/opn.12151.

15. Xu T, Clemson L, O'Loughlin K, Lannin NA, Dean C, Koh G. Risk factors for falls in community stroke survivors: a systematic review and meta-analysis. Arch Phys med Rehabil. 2018;99:563-573.

16. Schmid AA, Rittman M. Consequences of poststroke falls: activity limitation, increased dependence, and the development of fear of falling. Am J Occup Ther. 2009;63(3):310-316. doi:10.5014/ajot.63.3.310.

17. Gassert R, and Dietz V. Rehabilitation robots for the treatment of sensorimotor deficits: a neurophysiological perspective. J. Neuro Eng. Rehabil 2018;15:1-15.

18. Babaiasl M, Mahdioun SH, Jaryani P, Yazdani M. A review of technological and clinical aspects of robot-aided rehabilitation of upper-extremity after stroke. Disabil Rehabil Assist Technol. 2016;11(4):263-280. doi:10.3109/17483107.2014. 1002539

19. Fazekas G, Tavaszi I, Tóth A. [New Opportunities in Neurorehabilitation.. Ideggyogy Sz. 2016;69(56):148-154. doi:10.18071/isz.69.0148.

20. Poli P, Morone G, Rosati G, Masiero S. Robotic technologies and rehabilitation: new tools for stroke patients' therapy. Bio Med Res Int .2013:153872.

21. Mehrholz J, Hädrich A, Platz T, Kugler J, Pohl M. Electromechanical and robot-assisted arm training for improving generic activities of daily living, arm function, and arm muscle strength after stroke. Cochrane Database Syst Rev. 2012;(6):CD006876. Published 2012 Jun 13. doi:10.1002/14651858. CD006876.pub3.

22. Masiero S, Poli P, Rosati G, et al. The value of robotic systems in stroke rehabilitation. Expert Rev Med Devices. 2014;11(2):187-198. doi:10.1586/ 17434440.2014.882766.

23. Skvortsov DV. Clinical analysis of movements. Stabilometry. Moscow: AOZT Antidor. 2000.

24. Puszczalowska-Lizis E, Bujas P, Jandzis S, Omorczyk J, Zak M. Inter-gender differences of balance indicators in persons 60-90 years of age. Clin Interv Aging. 2018;13:903-912.

25. Ware JE, Kosinski M, Dewey JE. How to score version 2 of the SF-36 Health Survey (standard and acute forms). Second edition Lincoln RI: Quality Metric Inc; 2001.

26. Zigmond AS, Snaith RP. The hospital anxiety and depression scale. Acta Psychiatr Scand. 1983;67:361-370.
27. Mackintosh SF, Hill KD, Dodd KJ, Goldie PA, Culham EG. Balance score and a history of falls in hospital predict recurrent falls in the 6 months following stroke rehabilitation. Arch Phys Med Rehabil. 2006;87:1583-9.

28. Jalayondeja C, Sullivan PE, Pichaiyongwongdee S. Six-month prospective study of fall risk factors identification in patients post-stroke. Geriatr Gerontol Int. 2014;14:778-85.

29. Bower K, Thilarajah S, Pua YH ,Williams G, Tan D, Mentiplay B, Denehy L, Clark R. Dynamic balance and instrumented gait variables are independent predictors of falls following stroke. J Neuroeng Rehabil. 2019;16:3.

30. Harris JE, Eng JJ, Marigold DS, Tokuno CD, Louis CL. Relationship of balance and mobility to fall incidence in people with chronic stroke. Phys Ther. 2005;85:150-8.

31. Persson CU, Hansson PO, Sunnerhagen KS. Clinical tests performed in acute stroke identify the risk of falling during the first year: postural stroke study in Gothenburg (Postgot). J Rehabil Med. 2011;43:348-53.

32. Punt M, Bruijn SM, Wittink H, Van De Port IG, Van Dieën JH. Do clinical assessments, steady-state or daily-life gait characteristics predict falls in ambulatory chronic stroke survivors? J Rehabil Med. 2017;49:402-9.

33. Sawacha Z, Carraro E, Contessa P, Guiotto A, Masiero S, Cobelli C. Relationship Between clinical and instrumental balance assessments in chronic post-stroke hemiparesis subjects. J Neuroeng Rehabil. 2013;10:95.

34. Foster EJ, Barlas RS, Bettencourt-Silva JH, Clark AB, Metcalf AK, Bowles KM, Potter JF, Myint PK. Long-Term Factors Associated With Falls and Fractures Poststroke. Front Neurol. 2018 Apr 3;9:210. doi: 10.3389/fneur.2018.00210.

35. Callaly EL, Ni Chroinin D, Hannon N, Sheehan O, Marnane M, Merwick A, Kelly LA, Horgan G, Williams E, Harris D, Williams D, Moore A, Dolan E, Murphy S, Kelly PJ, Duggan J, Kyne L. Falls and fractures 2 years after acute stroke: the North Dublin Population Stroke Study. Age Ageing. 2015 Sep;44(5):882-6. doi: 10.1093/ageing/afv093.

36. Wei WE, De Silva DA, Chang HM, Yao J, Matchar $\mathrm{DB}$, Young SH, See SJ, Lim GH, Wong TH, Venketasubramanian N. Post-stroke patients with moderate function have the greatest risk of falls: A National Cohort Study. BMC Geriatr. 2019;19:373.

37. De Bujanda E, Nadeau S, Bourbonnais D. Pelvic and shoulder movements in the frontal plane during treadmill walking in adults with stroke. J Stroke Cerebrovasc Dis. 2004;13:58-69.

38. Kubryak OV, Grokhovsky SS, Isakova EV, Kotov SV. Biofeedback by reference reaction: methodology and therapeutic aspects. Moscow: Maska; 2015. 
39. Viccaro LJ, Perera S, Studenski SA. Is timed up and go better than gait speed in predicting health, function, and falls in older adults? J Am Geriatr Soc. 2011;59:887-92.

40. Cho KH, Lee GC. Impaired dynamic balance is associated with falling in post-stroke patients. Tohoku J Exp Med. 2013;230:233-9.

41. Verheyden GS, Weerdesteyn V, Pickering RM, Kunkel D, Lennon S, Geurts AC, Ashburn A. Interventions for preventing falls in people after stroke. Cochrane Database Syst Rev. 2013;CD008728.

42. Bendtsen L, Evers S, Linde M, Mitsikostas DD, Sandrini G, Schoenen J; EFNS. EFNS guideline on the treatment of tension-type headache - report of an EFNS task force. Eur J Neurol. 2010 Nov;17(11):1318-25. doi: 10.1111/j.14681331.2010.03070.x.

43. Jos YS, Menshikov IA. The possibility of using nanobiodevice to improve the functional abilities of the brain (review). Journal of biomedical research. 2019;3:338-348.

44. Kostenko E, Petrova L, Rylsky A, Zuev D, Gorshkov D. Features of correction of statolocomotor disorders in patients after stroke with emotional and cognitive disorders: randomized clinical open-label controlled study. Pharmateca. 2020;27:78-88.

45. Kołcz A, Urbacka-Josek J, Kowal M, Dymarek R, Paprocka-Borowicz M. Evaluation of Postural Stability and Transverse Abdominal Muscle Activity in Overweight Post-Stroke Patients: A Prospective, Observational Study. Diabetes Metab Syndr Obes. 2020 Feb 19;13:451-462. doi: 10.2147/DMSO.S235015.

46. Norouzi-Gheidari N, Hernandez A, Archambault PS, Higgins J, Poissant L, Kairy D. Feasibility,
Safety and Efficacy of a Virtual Reality Exergame System to Supplement Upper Extremity Rehabilitation Post-Stroke: A Pilot Randomized Clinical Trial and Proof of Principle. Int J Environ Res Public Health. 2019 Dec 23;17(1):113. doi: 10.3390/ijerph17010113.

47. Smith A, Ng A, Burgess ER, Weingarten N, Pacheco JA. Sensi-steps: using patient-generated data to prevent post-stroke falls. Amia Annu Symp Proc. 2017;2294-2298.

48. Chumbler NR, Li X, Quigley P, Morey MC, Rose D, Griffiths P, Sanford J, Hoenig H. A randomized controlled trial on stroke telerehabilitation: The effects on falls self-efficacy and satisfaction with care. J Telemed Telecare. 2015;21:139-43.

49. Masiero S, Armani M, Ferlini G, Rosati G, Rossi A. Randomized trial of a robotic assistive device for the upper extremity during early inpatient stroke rehabilitation. Neurorehabil Neural Repair. 2014;28(4):377-386. doi:10.1177/1545968313513073.

50. Lo K, Stephenson M, Lockwood C. Effectiveness of robotic assisted rehabilitation for mobility and functional ability in adult stroke patients: a systematic review. JBI Database System Rev Implement Rep. 2017;15(12):3049-3091. doi:10.11124/JBISRIR-2017-003456.

51. Doumas I, Everard G, Dehem S, Lejeune T. Serious games for upper limb rehabilitation after stroke: a meta-analysis. J Neuroeng Rehabil. 2021;18(1):100. Published 2021 Jun 15. doi:10.1186/s12984-021-00889-1.

52. Lin SH, Dionne TP. Interventions to Improve Movement and Functional Outcomes in Adult Stroke Rehabilitation: Review and Evidence Summary. J Particip Med. 2018;10(1):e3. Published 2018 Jan 18. doi:10.2196/jopm.8929.

Submission: September 18, 2020

Revision submitted: July 31, 2021 Accepted for publication: August 13, 2021 